\title{
Reflections on the Sports System of Primary and Middle Schools in Mainland China
}

\author{
Kai Shao \\ Panyapiwat Institute of Management \\ Nonthaburi, Thailand 11120
}

\begin{abstract}
This paper analyzes the sports system of primary and secondary schools in mainland China for more than 30 years by means of literature, comparative analysis and other methods. It is purposed to understand the characteristics and development trend of sports system in primary and secondary schools, and further discover the shortage of evaluation and supervision system for schools' sports System in view of mesoscopic system and microcosmic system, so as to change the downtrend of physical health of students and the deficient measures and system in primary and secondary schools. The campus sports facilities, equipment and physical education teacher training are the weak point of sports system of primary and secondary schools in mainland China, so this paper puts forward the corresponding countermeasures and suggestions.
\end{abstract}

Keywords-mainland China; primary and secondary schools; sports system; thinking

\section{INTRODUCTION}

System is the criterion of people's behavior in human society and people rely on the system to measure their own behavior. System is generally characterized by recognition, enforceability, relative stability and systematicness. In recent years, the physical health of students of primary and secondary school in China showed a downward trend, the academic community explores its causes and source from different viewpoints, to find the sports activities in schools are the main factors affecting students' physical health. And the key factor influencing the development of school sports is the schools' sports system, so this paper explores the reasons for the inefficiency of sports system in primary and secondary schools and puts forward the reform path to serve the schools' sports reform.

\section{ANALYSIS OF THE FACTORS AFFECTING THE PHYSICAL EDUCATION SYSTEM IN PRIMARY AND MIDDLE SCHOOLS}

First of all, organizational rigidity is an important factor affecting the changes of schools' sports system, and the school sports organization is also relatively complex, but reform is often ineffective, mainly because the important subject "teachers" and "students" of the organization rarely have the opportunity to participate in the reform, and the main decision making is limited in office of the system makers. Every member of the organization is silently doing their own things, and the changes around them seems hardly bring their interest. In the development process of school sports system, the members of the organization (teaching and research office) have little opportunity to make discussion together, and even if there is such an opportunity, the organizers (director of teaching and research office) often spread itself and other members of the organization seem to have nothing to do; in this way, "organizational rigidity" will affect the reform of schools' sports system.

Second, the conflict among the interest representatives of all parties of the school sports system is also affecting the reform of the school sports system; according to the different interests in the field of school sports, there may be different interest groups. The interest groups closely related to the school sports reform mainly include students, educators (including teachers and administrative staff) and governmental administrators of education. In the reform of school sports, whether it is macroscopic or microscopic, it ultimately has to make an effect on students. After all, in the reform of school sports, the interests of other groups should be also considered. Students establish their interest group for their own interests in order to fight for their interests; but in the current conditions of school education, students have very heavy class burden, and many students hope they can get rid of the boring learning of sports technology and physical training in the sport class, replaced by entertainment. At this point, the students formed their own interest group for their own interests and fight against the objectives of school sports training, greatly affecting the implementation of school sports system and hindering the reform of school sports. as professional sport teachers, educators have their common interest, they naturally form a certain group, while the reform of school sports is always carried out by educators, which will involve the comparison between their contribution of time and energy and their expected and actual earning. as a complex work, the school sports has been widely accepted by the community, but on the one hand the physical quality of young people has a serious decline, the state pays more and more attention to the physical quality of adolescents and gives more and more criticism for the sport work of schools, the voice for reform is also growing day by day, so all these bring large pressure for sport teachers of schools; on the other hand, the status of teachers is generally promoted, but they did not properly pay attention to the sports disciplines, they free control the sport class, sport teacher have little opportunity to participate in major decision-making and have relatively less welfare than that of the teachers of major subject, with a large gap, and the fund investment in sports is relatively deficient, 
etc., all of these have made the interest group of ports teachers had a negative cooperation on the reform of school sports system, which hindered the in-depth implementation of school sports system to a certain extent. The makers of the sports system are usually considered by the government as the representative of the interests of all the people and are the interest coordinators of various interest groups, but the government is run by officials, they constitute a special interest group for their own special interests in real life, and when they make decision for the reform of school sports, due to the limits of ability, the constraints of conditions and the principle of satisfaction, they can't make the decision achieve optimization, and only seek their greatest satisfaction of interests. Therefore, the limited rationality of national sports system makers is the key reason why the actual utility of school sports is inefficient and even null.

Third, the sports values are also one of the factors that affect the effectiveness of school sports system. Sports values exist between the subject of social activities and the object of sports, of which the object of sports acts on the subject of social activity in a way of its unique existence, and further causes the general view of subject on the social phenomenon of sports, and at the same time it also has different function for the different subjects that are engaged in sports activities. The sports values of PE teachers affect the professional attitude of teachers, whether their academic initiative is advancing with the times; while the students 'sports values determine their different conditions of participation and demand for sports activities. The sports managers' sports values have a specially important effect on the system, and it determines whether the direction of the sports development is scientific and reasonable; school sports managers may think that they are making a objective formulation of school sports system, but in fact, they should be making decision of the system under the guidance of the values formed by all the past experience.

Finally, physical exercise is another factor that chronically and deeply affects the school sports system. As Schumpeter said, if there is no habit, no one can cope with the daily work that must be done every day, and no one can survive even if one day. After years of education and teaching reform, school sports have formed a more scientific and mature system. However, some specific systems are facing the constraints of informal system in the implementation. In the actual education and teaching, due to the too heavy burden of students in studies, without enough time for physical exercise, so many students do not have the habit of physical exercise. Different understandings decide their different choice, but also affect their enthusiasm to participate in fitness, and of course, they will affect the development of their habit of exercise. The adolescent are at the important stage of growth and development, during which their personality is gradually improved, and the critical period also decides whether they can persevere in a life-long exercise. Therefore, in the reform of school sports, we should pay special attention to the development of students' habits of exercise, otherwise the implementation of school sports system will become a "mere scrap of paper."

\section{The EFFECTIVE MEASURes to ACtively Promote} THE SPORTS SYSTEM IN PRIMARY AND SECONDARY SCHOOLS

First, we should pertinently strengthen the construction of sports system for the physical health of young people. When formulating the system of school sports for the physical health of students in primary and secondary schools, the Government should properly delegate powers to the areas and schools at basic level, to make them give full play to their initiative and flexibility; according to the specific circumstances of students in physical health, constitute the relevant micro-system, strictly control the time of students for physical exercise during school, implement the supervision mechanism for students' physical exercise.

Second, we should strengthen the construction of "facilities" in sports venues and of teacher training management system. according to the development of school sports in each region, the government should allocate funds to the region with weak economic strength to help the schools to build site facilities and supporting teaching materials; according to the needs of schools for current sports development, arrange the regular training courses for PE teachers, constantly update the training content, broaden the international perspective of PE teachers, and make them actively participate in foreign exchange and actively explore the favorite sport class contents of students, develop the activities in a form that students are delighted with, and especially we should the sports management system of rural schools.

Third, the government should strengthen the implementation of management power, enhance the propaganda of sports concept in rural area, and develop the appropriate school sports system for rural area, especially make supervision of the development of sports curriculum in rural area, completely eradicate the free use of sport class by other class or the free-range activities of sport class, and strengthen the construction of relevant supervision and evaluation system of school sports in the mesoscopic and microcosmic view.

Fourth, strengthen the construction of school-based sports system, develop the school sports system with regional characteristics, and make implementation of this system under the system monitoring, develop the school sports items with local characteristics according to the local conditions, follow our school sports system, and explore the mesoscopic and microcosmic system of school sports suitable for regional characteristics.

Fifth, make combination of large data and the sports system of primary and secondary schools, vigorously promote the use of wisdom bracelet, in which the data of children's vital signs and the indicators of their daily activities are recorded, providing a feedback to the effectiveness of daily physical exercise and a monitoring of the actual effect of physical exercise, so as to ensure their one-hour exercise every day, making them develop good exercise habits. The bracelet can also prevent and greatly decrease the sudden safe incidents for all schools. 
Sixth, give a reasonable arrangements of sport-themed activities for students in the holiday, each school should arrange appropriate physical exercise task for students according to the different circumstances of the students, formulate the exercise programs and goals of stage, both promoting the physical health of students and training the good will and quality of students and promoting the intercollegiate communication as well as the development of local school-based sport curriculum in different periods.

\section{CONCLUSION}

When making the sports system of primary and secondary school, in order to maximize the efficiency of results, we should make the front-line professional PE teachers participate in the development of sport system, but also give full consideration to the actual exercise needs of students; arrange the school-based sport curriculum with local characteristics according to the local conditions; use the Internet data - the wisdom bracelet to support and guarantee the achievement of relevant work, providing effective quality control and the actual feedback of effectiveness; reasonably arrange the theme events in the holiday, improving sport teaching through lively activities, promoting the reform of sports system with high quality and full quantity in primary and secondary schools.

\section{REFERENCES}

[1] Li Dongmei. Thinking on the School Sport System in China[J]. Journal of Chengdu Sport University, 2009, 35 (10): 75-77. [J].

[2] Qian Jianlong. Analysis on China's School Sports System in Recent 36 Years [J]. Journal of Military Sports, 2016,35 (2): 62-66.

[3] Wang Zhe. The Status Quo of Physical Education Curriculum Setting in Primary and Secondary School and Its Reform Measures [J]. Neijiang Technology, 2008, (1): 186-187. 